\title{
The genetics of phenotypic plasticity in a colonizing population of the ladybird beetle, Harmonia axyridis
}

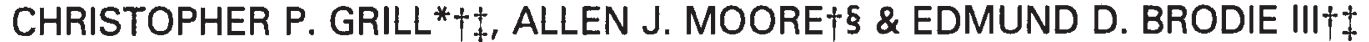 \\ †Center for Ecology, Evolution, and Behavior, $\ddagger$ T.H. Morgan School of Biological Sciences, 101 Morgan Building, \\ University of Kentucky, Lexington, KY 40506-0225 and §Department of Entomology, University of Kentucky, \\ Lexington, KY 40546-0091, U.S.A.
}

\begin{abstract}
We investigated the degree to which families of a colonizing ladybird beetle, Harmonia axyridis, differed in their phenotypic responses to familiar vs. novel food types using a split-brood fullsib design. Development time, adult size, and two measures of colour were significantly affected by diet. All traits measured were under some degree of genetic control. Significant levels of genetic variation existed in phenotypic plasticity for development time and adult size, but not for two measures of colour. Genetic correlations were found between several traits within single environments but no significant cross-environment genetic correlations were detected. We concluded that: (1) plasticity in development time and adult size may evolve given appropriate selection pressure; (2) plasticity in the two measures of colour cannot evolve owing to a lack of genetic variation; and (3) colonization of $H$. axyridis is associated with plasticity, though it is not clear that colonization events actively select for change in levels of plasticity.
\end{abstract}

Keywords: colonizing species, evolvability, genetics, $\mathrm{G} \times \mathrm{E}$ interaction, Harmonia axyridis, phenotypic plasticity.

\section{Introduction}

Phenotypic plasticity is thought to be associated with the ability to colonize new habitats (Parsons, 1983; Stearns, 1992), to overcome stressful environments (Hoffmann \& Parsons, 1991), and to adapt to unpredictable or novel resources (West-Eberhard, 1989). Many definitions of plasticity exist (Stearns, 1992); we define plasticity as the degree to which expression of a trait changes between environments for a particular genotype or family. Recent studies have shown that phenotypic plasticity is widespread in a variety of characters and species (Scheiner, 1993). Most of those studies have examined plasticity in samples from well-established populations. Few studies have examined the association between phenotypic plasticity and colonization (but see Futuyma et al., 1994).

Colonizing species face a number of different obstacles when spreading to new habitats where resources are often scarce, unpredictable, or novel.

*Correspondence: 101 T. H. Morgan Building, University of Kentucky, Lexington,KY 40506-0225,U.S.A.E-mail:cpg@ceeb.uky.edu
New habitats can be especially stressful for colonizers because of restrictions on food availability or quality that differ from those in the original environment (Parsons, 1983; Hoffmann \& Parsons, 1991). For colonizing species to be successful, they must have mechanisms or characters that allow them to overcome the obstacles associated with acquiring and utilizing resources in a new environment.

In the United States, an Asian species of ladybird beetle (Harmonia axyridis) has recently begun colonizing new habitats. This beetle was first introduced into the United States in California in 1916 (Gordon, 1985; Dreistadt et al., 1995) and was introduced recently into the south-eastern portion of the US in Georgia orchards for biological control of pecan aphids (Monellia caryella and Monelliopsis pecanis) (Tedders \& Schaefer, 1994). Over 87000 laboratory-reared individuals were released over the period from 1978 to 1981. Harmonia axyridis spread quickly from Georgia, and by $1992 H$. axyridis was reported in Kentucky (Tedders \& Schaefer, 1994; Potter et al., 1995). Large, well-established populations were present throughout northern and central Kentucky by 1994 (personal observations). Because $H$. axyridis has never been systematically released in 
Kentucky, the resident populations must be the result of recent migration events (Gordon, 1985). Thus, this Asian ladybird beetle is an excellent candidate for studying the association between phenotypic plasticity and colonization ability.

In particular, we are interested in how $H$. axyridis responds to a novel resource because we expect colonizing species to encounter resources in a new habitat that differ from those in the source population environment (Tedders \& Schaefer, 1994). In this study, we measured phenotypic and genetic variation, as well as plasticity, in development time from hatch to adulthood, pronotum width (as a measure of adult size), and two measures of colour in $H$. axyridis. All focal characters are known to be genetically variable (Dobzhansky, 1933; Osawa \& Nishida, 1992; Ueno, 1994). In addition, colour patterns can influence mate choice in $H$. axyridis (Osawa \& Nishida, 1992) and may also play a role in signalling unpalatability to potential predators (Edmunds, 1974). Thus, all focal characters are potentially related to fitness. If colonization ability of $H$. axyridis is associated with plasticity, we expect to see significant levels of plasticity in fitness-related characters in Kentucky populations.

\section{Materials and methods}

\section{Ladybird husbandry}

Several hundred adult and pupal $H$. axyridis (succinea morph) were collected from a single tobacco farm in Scott County, KY. All beetles were returned to the laboratory and placed individually in Petri dishes containing moist cotton plugs. Food was provided by placing $\approx 4 \mathrm{~cm}^{2}$ of tobacco (Nicotiana tabacum) infested with aphids (Myzus persicae) into each dish. Petri dishes were maintained in an incubator at $27^{\circ} \mathrm{C}$ with a 15:9 L:D photocycle. Food and water were checked every 2 days and replenished as necessary.

Following an acclimatization period of at least $24 \mathrm{~h}$ for adults, or at least one week after emergence to the adult stage for pupae, adult beetles were isolated in arbitrary male-female pairs and allowed to mate. After mating, females were isolated to prevent other adults from cannibalizing eggs. Newly laid eggs were separated from mated females every day and placed into new Petri dishes to hatch. Because newly hatched larvae are easily injured during transfer, hatchlings were left in their original dishes for 2 days and given unlimited access to water and aphids, after which families were split into different experimental treatments. Any common family environmental effects were thus limited to those occurring prior to the second day posthatch.

\section{Treatments}

Approximately half of the developing larvae from a given family were fed an unlimited diet of tobacco aphids (the aphid treatment [A]). The remaining larvae were provided with a synthetic blend of beef liver, ground beef and sucrose solution (the meat treatment $[M])$. The aphid diet mimics the natural diet of these ladybird beetles (Tedders \& Schaefer, 1994), whereas the meat diet simulates conditions under which food is abundant, but unfamiliar and of relatively low quality (T. Cottrell, unpublished data). The meat mixture was originally developed as an inexpensive food alternative to be used in massrearing of predaceous heteropterans for biological control applications (Cohen, 1985). After being assigned to treatments, all larvae were raised individually in Petri dishes to prevent cannibalism.

\section{Focal traits}

Effects of environment may greatly influence the speed with which maturity is reached or the developmental pathways chosen during ontogeny. As a gross measure of this environmental effect, we measured development time (DEVTIME) in days from egg hatch to adult emergence in each environment.

Because beetle growth is determinate, morphological characters make reasonable indicators of adult body size. Thus, pronotum width (SIZE) was measured via image analysis as an indicator of adult body size. All measurements were made using a Power Macintosh 8500 computer and the public domain NIH Image analysis package (download at http://rsb.info.nih.gov/nih-image/ or ftp//zippy.nimh .nih.gov/pub/). Measures of pronotum widths using image analysis were highly repeatable within individuals $(r=0.98 ; n=15$ beetles with 2 measurements per beetle).

All $H$. axyridis at our collection site were of the colour morph succinea which is homozygous recessive for predominantly orange, rather than black, elytra or wing coverings (Komai, 1956). Colour was measured using a Spectator portable spectroradiometer with a standardized tungsten halogen light source (Ocean Optics LS-1 tungsten halogen lamp). All reflectance readings were taken at right angles to the surface of the elytra at a distance of $2 \mathrm{~mm}$ using a fibre optic probe. Because spectral properties of $H$. axyridis change after death, measurements of reflectance were made on live animals only. Meas- 
urements were made $\approx 2 \mathrm{~mm}$ from the posterior end of the body. We analysed differences in the main elytron colour (orange or red); reflectance of black spots was not measured. Reflectance spectra indicated two consistent peaks on all animals corresponding to orange $(612.8 \mathrm{~nm})$ and red $(674.7 \mathrm{~nm})$ wavelengths. Two measures of reflectance were taken for each wavelength (ORANGE and RED) from each individual. Repeatabilities of measurements within individuals were high $(r=0.79 ; n=234$ beetles with 2 measurements per beetle); average reflectance at each wavelength was used as the measure of individual reflectance in subsequent analyses.

\section{Genetic analyses within environments}

Our breeding design and experimental set-up yielded full-sib data for all traits under the two different environmental conditions. Thus, we implicitly include the assumption that maternal, common-family, and nonadditive genetic effects are negligible (Falconer, 1989). Heritabilities within a given environmental treatment were calculated from the full-sib data using ANOVA following Becker (1992):

$Y_{i k}=\mu+\alpha_{i}+e_{i k}$

where $\mu$ is the common mean, $\alpha_{i}$ is the effect of the $i$ th family, and $e_{i k}$ is the uncontrolled environmental and genetic deviations attributable to the $i$ th male with a single dam and sire. We corrected for unbalanced numbers of individuals per family using:

$n_{0}=\left(\frac{1}{S-1}\right)\left(n_{t}-\left(\frac{\Sigma n_{i}^{2}}{n_{t}}\right)\right)$,

where $n_{0}$ is the corrected number of offspring per family used in calculating the expected mean squares, $S$ is the number of families, $n_{t}$ is the total number of offspring and $n_{i}$ is the number of offspring in family $i$ (Becker, 1992). Heritabilities were calculated as:

$h^{2}=\frac{2 V_{\mathrm{S}}}{V_{\mathrm{P}}}$,

where $V_{\mathrm{S}}$ is the among-family variance and $V_{\mathrm{P}}$ is the total phenotypic variance. Standard errors of heritabilities were calculated as:

$\mathrm{SE}\left(h^{2}\right)=2 \sqrt{\frac{2\left(n_{t}-1\right)(1-t)^{2}\left[1+\left(n_{0}-1\right) t\right]^{2}}{n_{0}^{2}\left(n_{t}-S\right)(S-1)}}$, where $t$ is the intraclass correlation and all other variables are as above (Becker, 1992).

Heritability of a trait standardizes the measured genetic variation relative to the total phenotypic variation. Houle (1992) suggested that heritability is not the most appropriate measure of genetic variation in some cases, especially under directional or weak stabilizing selection regimes. Evolvabilities are alternative measures of genetic variation which are standardized by the means of the traits of interest (Houle, 1992). We estimate evolvability from the coefficient of genetic variation $\left(C V_{\mathrm{G}}\right)$ :

$C V_{\mathrm{G}}=100 \frac{\sqrt{V_{\mathrm{G}}}}{\bar{X}}$

where $V_{\mathrm{G}}$ is the genetic variation calculated from full-sib data.

For characters expressed in the same environment (e.g. SIZE ${ }_{\mathrm{A}}$ and $\mathrm{RED}_{\mathrm{A}}$ ), we calculated genetic correlations $\left(r_{\mathrm{G}}\right)$ using covariances calculated from sums of cross-products estimates (Becker, 1992) as follows:

$r_{\mathrm{G}}=\frac{\operatorname{Cov}(X, Y)}{\sqrt{\operatorname{Var}(X) \operatorname{Var}(Y)}}$,

where $\operatorname{Cov}(X, Y)$ is the covariance between two traits, $X$ and $Y$; $\operatorname{Var}(X)$ and $\operatorname{Var}(Y)$ are the full-sib genetic variance estimates for each trait. Significance (i.e. difference from zero) was calculated as described in Brodie (1989).

An alternative approximation of genetic correlations can be calculated on family mean data (Via, 1984). Genetic correlations based on family means $\left(r_{\mathrm{FM}}\right)$ are calculated as:

$r_{\mathrm{FM}}=\frac{\operatorname{Cov}(X, Y)}{\sqrt{\operatorname{Var}(X) \operatorname{Var}(Y)}}$,

where $\operatorname{Cov}(X, Y)$ is the covariance between the fullsib, within-environment family means of traits $X$ and $Y$; $\operatorname{Var}(X)$ and $\operatorname{Var}(Y)$ are the full-sib genetic variance estimates for each trait. Because family sizes were not all equal, cross-environment correlation results should be viewed only as qualitative indicators of correlation patterns.

\section{Genetic analyses of plasticity}

Two methods have been proposed for studying genetic variation in phenotypic plasticity. One, first proposed by Falconer (1952), treats a trait expressed 
in two different environments as two different traits (character states); a genetic correlation is estimated for the expression of the trait under the two environmental conditions. An alternative is the use of ANOVA to calculate genotype by environment interaction terms $(\mathrm{G} \times \mathrm{E})$; a mixed-model ANOVA is preferred for this approach (Fry, 1992). It is not clear which of these approaches yields the more informative data (Schlichting \& Pigliucci, 1995; Via \& Conner, 1995); the current practice has been to present both estimates (e.g. Via \& Conner, 1995). For evolutionary interpretations, the genetic correlation approach may have the advantage of providing estimates that more directly indicate the potential for evolution to proceed independently in different environments (Via, 1984, 1987; Via \& Conner, 1995).

We estimated genetic correlations across environments with family mean correlations $\left(r_{\mathrm{FM}}\right)$ for each trait expressed in the two environments (i.e. character state correlations). In addition to the expression of the same trait in different environments, different traits or characters expressed in the same or different environments may constrain the evolution of genetically correlated characters (Lande, 1979). We therefore calculated family mean correlations for all pairwise combinations of each trait expressed in one environment with all remaining traits expressed in the other environment.

Genotype by environment (or in our experiment, family by treatment) interactions were calculated using mixed-model ANOVA in which genotype (family) was a random effect and environment (treatment) was a fixed effect (Fry, 1992). Significant main effects of genotype indicate familial differences in trait values correlated with environment (Fry,
1992). Significant main effects of environment indicate that, on average, the population demonstrates plasticity in response to the different environments. Significant family by treatment interactions indicate variation in the level of plasticity between families. In analyses of plasticity involving only two environments, tests for interactions are essentially equivalent to tests for genetic correlations between character states (Via, 1987; Itoh \& Yamada, 1990; but see Schlichting \& Pigliucci, 1995).

Whereas adult size was significantly different between males and females, no other characters differed significantly between sexes. Because no sex-specific differences in character expression depended on the treatment in which they occurred (i.e. no sex by treatment interactions), all analyses were performed on data adjusted to a common (female) mean (cf. Brodie, 1993). Prior to any analyses, assumptions were tested using Lillifoers tests and graphical inspection of data. Data were normally distributed before (size) or after log transformation (development time, colour). All statistical analyses were performed using the SYSTAT statistical package (Wilkinson, 1990). Statistical significance of the random effect (FAMILY) in mixed-model ANOVAS was tested using the interaction sums of squares components as outlined in Fry (1992).

\section{Results}

\section{Heritabilities and evolvabilities within environments}

In the aphid treatment, heritability was low for size and intermediate for development time and both measures of colour (Table 1). In the meat treatment, heritability was low for reflectance of orange and

Table 1 Means, heritabilities, and evolvabilities of focal characters of Harmonia axyridis in each treatment

\begin{tabular}{|c|c|c|c|c|c|c|c|}
\hline Character & Mean \pm SD & Units & $\begin{array}{l}\text { Number of } \\
\text { families }\end{array}$ & $\begin{array}{l}\text { Adjusted } \\
\text { family sizes }\end{array}$ & $h^{2}$ & SE & Evolvability \\
\hline \multicolumn{8}{|l|}{ Aphid } \\
\hline DEVTIME & $15.3 \pm 1.1$ & (days) & 22 & 6.38 & 0.671 & 0.198 & 6.054 \\
\hline SIZE & $2.99 \pm 0.15$ & $(\mathrm{~mm})$ & 22 & 5.95 & 0.221 & 0.153 & 1.974 \\
\hline ORANGE & $46.2 \pm 16.1$ & (\% reflectance) & 23 & 5.95 & 0.568 & 0.190 & 24.29 \\
\hline RED & $47.4 \pm 14.9$ & (\% reflectance) & 23 & 5.95 & 0.491 & 0.184 & 21.37 \\
\hline \multicolumn{8}{|l|}{ Meat } \\
\hline DEVTIME & $17.9 \pm 2.4$ & (days) & 26 & 4.91 & 0.754 & 0.194 & 11.11 \\
\hline SIZE & $2.87 \pm 0.20$ & $(\mathrm{~mm})$ & 26 & 5.13 & 0.615 & 0.195 & 4.645 \\
\hline ORANGE & $49.8 \pm 19.7$ & (\% reflectance) & 26 & 5.13 & 0.063 & 0.133 & 39.43 \\
\hline RED & $50.5 \pm 18.2$ & (\% reflectance) & 26 & 5.13 & 0.017 & 0.125 & 40.38 \\
\hline
\end{tabular}

Because number of offspring per family was not constant, calculations were performed using adjusted family sizes as described in Becker (1992). 
red, but high for development time and size (Table 1). Patterns of evolvability values were quite different from those for heritabilities; evolvabilities were relatively similar across environments and were low for development time and size, but high for reflectances of orange and red (Table 1).

\section{Genetic analyses within environments}

In the aphid treatment, there were no significant genetic correlations between any characters except for reflectances of orange and red. Both the family mean correlation and the standard genetic correlation between reflectance of orange and of red were significant and nearly one (Table 2).

In the meat treatment, both family mean correlations and standard genetic correlations indicate that most characters were not significantly genetically correlated. In contrast to the pattern found in the aphid treatment, however, a strong negative genetic correlation existed between development time and adult size. Consistent with the results found in the aphid treatment, a very strong and significant positive genetic correlation existed between reflectances of orange and red (Table 2).

\section{Genetic analyses between environments}

Family mean correlations between character states (i.e. the same trait expressed in different environ- ments) were moderately strong for development time, and reflectances of both orange and red; the family mean correlation between the two character states of size was relatively weak (Table 3 ). The correlation between size in the aphid treatment and both measures of colour in the meat treatment was much greater than the correlation between size in the meat treatment and either measure of colour in the aphid treatment (Table 3). In addition, the correlation between development time in the aphid treatment and size in the meat treatment was much stronger than the correlation between development

Table 3 Family mean correlations $\left(r_{\mathrm{FM}}\right)$ of characters between environments for Harmonia axyridis

\begin{tabular}{lcccc}
\hline & DEVTIME $_{\mathrm{A}}$ & SIZE $_{\mathrm{A}}$ & ORANGE $_{\mathrm{A}}$ & RED $_{\mathrm{A}}$ \\
\hline DEVTIME $_{\mathrm{M}}$ & 0.420 & -0.046 & 0.132 & 0.143 \\
& $(0.041)$ & $(0.830)$ & $(0.538)$ & $(0.504)$ \\
SIZE $_{\mathrm{M}}$ & -0.317 & 0.126 & 0.033 & 0.029 \\
& $(0.131)$ & $(0.559)$ & $(0.878)$ & $(0.892)$ \\
ORANGE $_{\mathrm{M}}$ & -0.105 & 0.396 & 0.442 & 0.446 \\
& $(0.626)$ & $(0.056)$ & $(0.031)$ & $(0.029)$ \\
RED $_{\mathrm{M}}$ & -0.120 & 0.372 & 0.430 & 0.443 \\
& $(0.577)$ & $(0.074)$ & $(0.036)$ & $(0.030)$ \\
\hline
\end{tabular}

Environments: A, aphid diet; M, meat diet.

Unadjusted $P$-values in parentheses.

Table 2 Genetic correlations $\left(r_{\mathrm{G}}\right)$ with standard errors (SE), family mean correlations $\left(r_{\mathrm{FM}}\right)$ with associated unadjusted $P$-values, phenotypic correlations $\left(r_{\mathrm{P}}\right)$, and environmental correlations $\left(r_{\mathrm{E}}\right)$ between different characters of Harmonia axyridis in each treatment

\begin{tabular}{|c|c|c|c|c|c|c|c|c|}
\hline Trait pairs & $\begin{array}{l}\text { Number of } \\
\text { families }\end{array}$ & $\begin{array}{l}\text { Adjusted } \\
\text { family sizes }\end{array}$ & $r_{\mathrm{G}}$ & SE & $r_{\mathrm{FM}}$ & $P$-values & $r_{\mathrm{P}}$ & $r_{\mathrm{E}}$ \\
\hline \multicolumn{9}{|l|}{ Aphid } \\
\hline SIZE, DEVTIME & 22 & 6.09 & -0.320 & 0.286 & 0.005 & 0.981 & -0.187 & -0.125 \\
\hline SIZE, RED & 22 & 6.38 & 0.091 & 0.358 & 0.258 & 0.223 & 0.101 & 0.110 \\
\hline SIZE, ORANGE & 22 & 6.38 & 0.140 & 0.334 & 0.335 & 0.110 & 0.121 & 0.121 \\
\hline DEVTIME, RED & 23 & 5.95 & 0.464 & 0.183 & 0.422 & 0.040 & 0.115 & -0.369 \\
\hline DEVTIME, ORANGE & 23 & 5.95 & 0.363 & 0.191 & 0.402 & 0.052 & 0.117 & -0.283 \\
\hline RED, ORANGE & 23 & 5.95 & 0.983 & 0.008 & 0.973 & $<0.001$ & 0.982 & 0.986 \\
\hline \multicolumn{9}{|l|}{ Meat } \\
\hline SIZE, DEVTIME & 26 & 4.91 & -0.947 & 0.021 & -0.845 & $<0.001$ & -0.664 & 0.032 \\
\hline SIZE, RED & 26 & 4.91 & 0.777 & 0.319 & -0.100 & 0.607 & 0.087 & -0.038 \\
\hline SIZE, ORANGE & 26 & 4.91 & 0.509 & 0.392 & -0.084 & 0.664 & 0.093 & -0.034 \\
\hline DEVTIME, RED & 26 & 5.13 & -0.736 & 0.449 & 0.144 & 0.457 & -0.007 & 0.154 \\
\hline DEVTIME, ORANGE & 26 & 5.13 & -0.338 & 0.463 & 0.153 & 0.429 & -0.009 & 0.135 \\
\hline RED, ORANGE & 26 & 5.13 & 1.187 & $0.003^{*}$ & 0.993 & $<0.001$ & 0.995 & 0.996 \\
\hline
\end{tabular}

Because number of offspring per family was not constant, calculations were performed using adjusted family sizes as described in Becker (1992).

${ }^{*}$ Calculated based on $r_{\mathrm{G} \text { (RED, ORANGE) }} \approx 1.0$ in the meat treatment. 
time in the meat treatment and size in the aphid treatment. Finally, there was a significant positive correlation of each measure of colour from the aphid treatment with the other measure of colour from the meat treatment (Table 3).

\section{Analysis of variance and $G \times E$ interactions}

Development time was significantly affected by family and treatment (Fig. 1a, Table 4). The effect of the treatment was relatively consistent in that development time was shorter in the aphid treatment than the meat treatment for all families but one. The family by treatment interaction was also significant, indicating that genetic variation existed for plasticity in development time (Fig. 1a, Table 4).

Pronotum width was not significantly affected by family but did depend on treatment. Beetles reared in the aphid treatment were usually, though not always, larger than their sibs raised in the meat treatment. The family by treatment interaction was also significant, indicating that genetic variation existed for plasticity in pronotum width (Fig. 1b, Table 4).

Reflectance of orange was affected significantly by family and environment but the family by treatment interaction was not significant. Reflectance of orange was usually, though not always, higher in the meat treatment than in the aphid treatment. Results were similar for reflectance of red (Fig. 1c,d; Table 4).

\section{Discussion}

\section{Variation and inheritance of adult mass, development and colour}

All characters measured were variable and the variation had an underlying genetic basis. Expression of all traits was affected by the diet on which the beetles were reared. Measured characters did not differ, on average, between sexes with the exception of size. Differences in trait expression between sexes did not depend on the environment in which they were expressed.

Within the aphid treatment, development time and reflectances of orange and red had intermediate heritabilities whereas size had relatively low heritability. In the meat treatment, however, development time and size had high heritabilities whereas reflectances of both orange and red had low heritabilities. Thus, patterns of heritability were not consistent between environments. Our results add to the growing body of literature suggesting that heritabilities can be strongly environment-dependent (see review by Hoffmann et al., 1995).
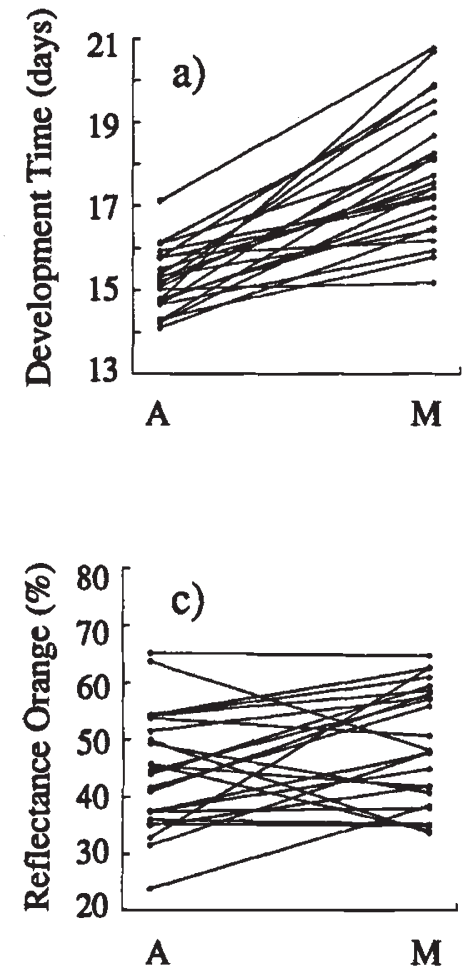
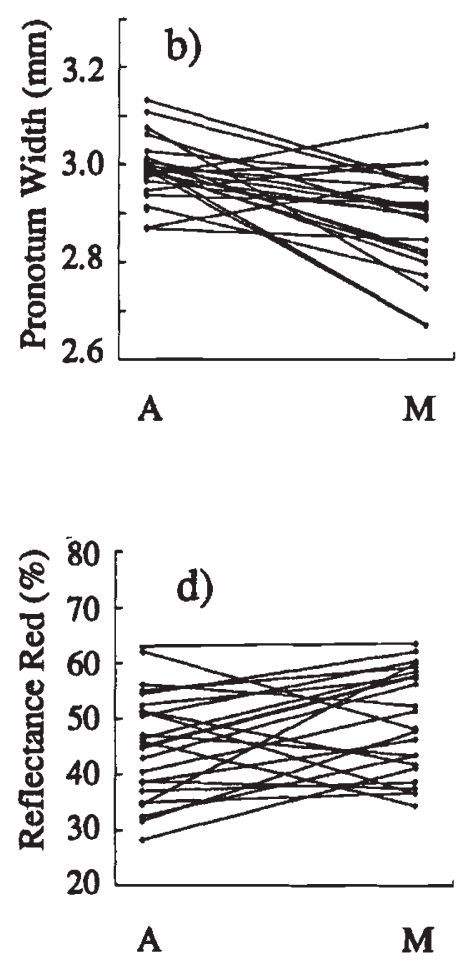

Fig. 1 Reaction norms of Harmonia axyridis for: (a) development time; (b) pronotum width; (c) percentage reflectance of orange; and (d) percentage reflectance of red. Each line represents the mean reaction norm for one family. The slope of the reaction norm line may be thought of as the magnitude and direction of phenotypic plasticity for a given family. A, aphid diet; $\mathrm{M}$, meat diet. 
Table 4 Two-way ANova tables for DEVTIME, SIZE, ORANGE and RED traits in Harmonia axyridis

\begin{tabular}{llrcrr}
\hline Dependent & Source & d.f. & MS & $F$ & $P$ \\
\hline DEVTIME & FAMILY & 23 & 0.051 & 2.821 & $<0.001$ \\
& TREAT & 1 & 1.680 & 209.971 & $<0.001$ \\
& F $\times$ T & 23 & 0.018 & 2.251 & 0.001 \\
& Error & 354 & 0.008 & & \\
SIZE & FAMILY & 23 & 0.069 & 1.342 & 0.243 \\
& TREAT & 1 & 0.983 & 36.635 & $<0.001$ \\
& F $\times$ T & 23 & 0.051 & 1.912 & 0.008 \\
& Error & 351 & 0.027 & & \\
ORANGE & FAMILY & 21 & 0.397 & 2.363 & 0.028 \\
& TREAT & 1 & 0.619 & 4.200 & 0.042 \\
& F $\times$ T & 21 & 0.168 & 1.139 & 0.308 \\
& Error & 234 & 0.147 & & \\
RED & FAMILY & 21 & 0.293 & 2.259 & 0.034 \\
& TREAT & 1 & 0.513 & 4.166 & 0.042 \\
& F $\times$ T & 21 & 0.130 & 1.052 & 0.402 \\
& Error & 234 & 0.123 & & \\
\hline
\end{tabular}

Effects of treatment were tested using error mean squares; effects of family were tested using $\mathrm{F} \times \mathrm{T}$ interaction mean squares as described in Fry (1992). Significant results in italic.

Heritability estimates may be biased by underlying differences in environmental variance, even if genetic variance for focal characters is similar. If comparisons of genetic variation are to be made between characters, those characters must be standardized to a common scale and differences in their underlying phenotypic variance must be taken into account (Houle, 1992). This is especially true when comparisons are made for traits expressed in different environments, or for interspecific comparisons (Cheverud, 1996). If environments differ, differences in heritability may not reveal anything about differences in genetic variation for the characters being compared. In such cases, measures of 'evolvability', especially coefficients of additive genetic variation, may be more relevant (Houle, 1992).

Houle (1992) and Messina (1993) found that heritabilities and evolvabilities were often markedly different within a single environment. Our results are similar to those of Houle (1992) and Messina (1993) in that patterns of evolvability do not match those of heritability. Both development time and size show low evolvabilities whereas reflectances of orange and red show relatively high evolvabilities. Furthermore, in contrast to patterns of heritability, patterns of evolvability were consistent between environments (Table 1). Our results suggest that, as with interspecific comparisons of genetic variation (Cheverud, 1996), evolvability may provide a more consistent estimate of the genetic variation underlying focal traits than heritability in studies involving multiple environments.

\section{Genetics of phenotypic plasticity within environments}

Most characters were not strongly correlated within either environment. However, reflectances of orange and red were strongly correlated in both environments, suggesting that these two measures are essentially inherited as a single trait. An additional exception was the strong negative genetic correlation between size and development time in the meat treatment. In our study, individuals that inherited short development time also tended to inherit large body size. This negative genetic correlation does not represent a trade-off; some families tended to develop to adulthood in relatively few days and grow to a relatively large size, whereas other families tended to develop to adulthood in relatively many days and grow to a relatively small size. Thus, development time and adult body size were negatively correlated in terms of actual values, but positively correlated in terms of performance. Because this strong negative genetic correlation occurred 
only in the meat treatment, it is likely that the relatively low quality of this treatment exaggerated differences in quality between families.

\section{Genetics of phenotypic plasticity between environments}

Significant effects of environment indicate that a population is, on average, responding differently to each environment. Knowledge of population-level plasticity patterns reveals little, however, about the potential for evolution of phenotypic plasticity. In this case, significant main effects of environment simply indicate that expression of the measured trait changes between environments and warrants additional investigation.

Variability in the level of plasticity can be estimated using the $\mathrm{G} \times \mathrm{E}$ interaction term as an indicator of interfamilial differences in reaction norm slopes (Via, 1987, 1994). A significant $G \times E$ interaction indicates that variation exists between families in the level of plasticity for the focal plastic trait. A significant $\mathrm{G} \times \mathrm{E}$ interaction does not necessarily mean that variation in plasticity is sufficient to allow evolution to some optimal level, nor does it mean that evolution will even occur. However, with some limitations, the $\mathrm{G} \times \mathrm{E}$ interaction can be used to infer how much genetic variation exists for phenotypic plasticity (e.g. Via, 1987). In our study, variation existed for the level of plasticity expressed for development time and pronotum width, but not for either measure of colour.

An alternative approach is to measure genetic correlations between family means of a focal trait expressed in the two environments (Via, 1987; Via \& Conner, 1995). Such a correlation reflects the degree to which independent evolution of the focal trait can occur in different environments (Via, 1987, 1994). The main weakness of this approach is that low family sizes may result in biased estimates (Via, 1984). Our between-environment genetic correlations were not particularly strong, but these results may reflect both our relatively small number of families ( $n=22-26$ families) and in some cases, small family sizes (Via, 1984; Via \& Conner, 1995).

Our results suggest that evolution of phenotypic plasticity in development time and size is possible. Both traits exhibited underlying genetic variability for phenotypic plasticity. Correlations between character states are unlikely to preclude evolution of plasticity in development time and size, assuming selection on the level of plasticity. Conversely, plasticity in reflectance of orange and red is unlikely to evolve, even in the face of strong selection, because no genetic variation was detected in the level of plasticity for reflectance of either colour.

\section{Potential evolutionary consequences of colonization}

Our study provides evidence that $H$. axyridis displays phenotypic plasticity in several important characters, as would be expected for a colonizing species. All measured characters show some degree of plasticity at the population level and this plasticity has a genetic basis. Genetic correlations between measured characters do not appear to pose a constraint on evolution of plasticity in those characters. Because Kentucky populations arrived very recently, it is unlikely that current levels of plasticity are the result of selection in the new habitat. A more likely scenario is that beetles that possess high levels of plasticity with a genetic basis are predisposed to successful colonization. Whether the colonization event itself actively selects for changes in the level of plasticity in colonizing populations remains to be seen.

Understanding the proximate causes of phenotypic plasticity becomes more complex in species with a recent history of colonization events. Comparisons between colonizing and established populations are needed to address questions about the role of plasticity in facilitating colonization and range expansion. The recent spread of $H$. axyridis throughout the south-eastern United States suggests that this species frequently encounters new habitats, climates, resources and selection pressures. The extensive genetic variation underlying a variety of characters makes this species an ideal candidate for future studies addressing the nature of evolutionary changes in phenotypic plasticity.

\section{Acknowledgements}

We thank R. Wallin for access to the Hicks-Wallin farm for collection of insects. T. Cottrell provided invaluable advice on collection and husbandry of ladybird beetles. We thank W. Wallin for expert technical assistance. G. Adkison, S. DeBano, T. DeWitt, K. Haynes, P. O'Neill, V. Rush, J. Wagner, D. Wise, J. Wolf and two anonymous reviewers provided useful comments and suggestions that greatly improved the quality of this manuscript. CPG was supported financially by a T. H. Morgan School of Biological Sciences Summer Fellowship, NSF-KY EPSCoR Grant EHR-9108764, and a Sigma Xi Grant-in-Aid of Research. Additional support was provided by NSF grants DEB-9107078 
and DEB-9521821, as well as state and federal Hatch funds to AJM.

\section{References}

BECKER, w. A. 1992. Manual of Quantitative Genetics, 5th edn. Academic Enterprises, Washington.

BRODIE, E. D., 111. 1989. Genetic correlations between morphology and antipredator behaviour in natural populations of the garter snake Thamnophis ordinoides. Nature, 342, 542-543.

BRODIE, E. D., 111. 1993. Homogeneity of the genetic variance-covariance matrix for antipredator traits in two natural populations of the garter snake Thamnophis ordinoides. Evolution, 47, 844-854.

CHEVERUD, J. M. 1996. Quantitative genetic analysis of cranial morphology in the cotton-top (Saguinus oedipus) and saddle-back (S. fusciollis) tamarins. J. Evol. Biol., 9, $5-42$.

COHEN, A. C. 1985. Simple method for rearing the insect predator Geocoris puntipes (Heteroptera: Lygaeidae) on a meat diet. J. Econ. Entomol., 78, 1173-1175.

DOBZHANSKY, T. 1933. Geographical variation in ladybeetles. Am. Nat., 67, 97-126.

DREISTADT, S. H., HAGEN, K. S. AND BEZARK, L. G. 1995. Harmonia axyridis (Pallas) (Coleoptera: Coccinellidae), first western United States record for this Asiatic lady beetle. Pan-Pacific Ent., 71, 135-136.

EDMunds, M. 1974. Defence in Animals. Longman, New York.

FALCONER, D. S. 1952. The problem of environment and selection. Am. Nat., 86, 293- 298.

FALCONER, D. S. 1989. Introduction to Quantitative Genetics, 3rd edn. John Wiley and Sons, New York.

FRY, J. D. 1992. The mixed-model analysis of variance applied to quantitative genetics: biological meaning of the parameters. Evolution, 46, 540-550.

FUTUYMA, D. J., KEESE, M. C. AND SCHEFFER, S. J. 1994. Genetic constraints and the phylogeny of insect-plant associations: responses of Ophraella communa (Coleoptera: Chrysomelidae) to host plants of its congeners. Evolution, 47, 888-905.

GORDON, R. D. 1985. The Coccinellidae (Coleoptera) of America north of Mexico. J. New York Entomol. Soc., 93, 1-912.

HOFFMANN, A. A. AND PARSONS, P. A. 1991. Evolutionary Genetics and Environmental Stress. Oxford University Press, New York.

hOFFMANN, A. A., SGRO, C. M. AND LAWLER, S. H. 1995. Ecological population genetics: the interface between genes and environment. Ann. Rev. Genet., 29, 349-370.

HOULE, D. 1992. Comparing evolvability and variability of quantitative traits. Genetics, 130, 195-204.

ITOH, Y. AND YAMADA, Y. 1990. Relationships between genotype $\times$ environment interaction and the genetic correlation of the same trait measured in different environments. Theor. Appl. Genet., 80, 11-16.

комA1, т. 1956. Genetics of ladybirds. Adv. Genet., 8, $155-188$.

LANDE, R. 1979. Quantitative genetic analysis of multivariate evolution, applied to brain:body size allometry. Evolution, 33, 402-416.

MESSINA, F. J. 1993. Heritability and 'evolvability' of fitness components in Callosobruchus maculatus. Heredity, 71, 623-629.

OSAWA, N. AND NISHIDA, T. 1992. Seasonal variation in elytral colour polymorphism in Harmonia axyridis (the ladybird beetle): the role of non-random mating. Heredity, 69, 297-307.

PARSONS, P. A. 1983. The Evolutionary Biology of Colonizing Species. Cambridge University Press, New York.

POTTER, M. F., BESSIN, R. T. AND TOWNSEND, L. H. 1995. Asian lady beetle infestation of structures. ENTFACT no. 64, Cooperative Extension Service, College of Agriculture, University of Kentucky, Lexington, KY.

SCHEINER, S. M. 1993. Genetics and evolution of phenotypic plasticity. Ann. Rev. Ecol. Syst., 24, 35-68.

SCHLICHTING, C. D. AND PIGLIUCCl, M. 1995. Gene regulation, quantitative genetics and the evolution of reaction norms. Evol. Ecol., 9, 154-168.

STEARNS, s. C. 1992. The Evolution of Life Histories. Oxford University Press, New York.

TEDDERS, w. L. AND SCHAEFER, P. w. 1994. Release and establishment of Harmonia axyridis (Coleoptera: Coccinellidae) in the southeastern United States. Entomol. News, 105, 228-243.

UENO, H. 1994. Genetic estimations for body size characters, development period and development rate in a Coccinellid beetle, Harmonia axyridis. Res. Popul. Ecol., 36, 121-124.

VIA, s. 1984. The quantitative genetics of polyphagy in an insect herbivore. II. Genetic correlations in larval performance within and among host plants. Evolution, 38, 896-905.

VIA, s. 1987. Genetic constraints on the evolution of phenotypic plasticity. In: Loeschcke, V. (ed.) Genetic Constraints on Adaptive Evolution, pp. 47-71. SpringerVerlag, Berlin.

V1A, s. 1994. The evolution of phenotypic plasticity: what do we really know? In Real, L. A. (ed.) Ecological Genetics, pp. 35-57. Princeton University Press, Princeton, NJ.

VIA, S. AND CONNER, J. 1995. Evolution in heterogeneous environments: genetic variability within and across different grains in Tribolium castaneum. Heredity, 74, $80-90$.

weSt-eberhard, M. J. 1989. Phenotypic plasticity and the origins of diversity. Ann. Rev. Ecol. Syst., 20, 249-278.

WILKINSON, L. 1990. SYSTAT, The System for Statistics. Systat, IL. 